\title{
INVESTIGATION OF VELOCITY SENSING IN HARVESTERS FOR MAGNETORHEOLOGICAL DAMPERS
}

\author{
Bogdan SAPIŃSKI*, Andrzej MATRAS ${ }^{*}$ \\ *AGH University of Science and Technology, Department of Process Control, al. Mickiewicza 30, 30-059 Cracow, Poland \\ *AGH University of Science and Technology, Department of Power Electronics and Energy Control Systems, \\ al. Mickiewicza 30, 30-059 Cracow, Poland \\ deep@agh.edu.pl,matras@agh.edu.pl
}

received 21 December 2017, revised 31 July 2018, accepted 3 August 2018

\begin{abstract}
This paper investigates the performance of electromagnetic vibration harvesters that can be incorporated in energy harvesting magnetorheological (MR) dampers. The study outlines the structure and operating principles of harvesters and compares results of numerical calculations with measurement data obtained under idle run. Results demonstrate the potential applications of harvesters as velocity sensors. The relationship between electromotive force (emf) and velocity across the devices is established. The discussion section suggests that power generation by harvesters can provide the velocity information by utilising the sensing function applicable to a variety of control algorithms.
\end{abstract}

Key words: Harvester, Electromotive Force, Velocity, Sensor

\section{INTRODUCTION}

Available sources of energy to be recovered from the surroundings include vibration of the diverse objects: machinery and equipment, vehicles, engineering structures, etc. Their vibration energy can be converted into electricity via harvesters whose operating principles rely on various types of conversion mechanisms. One of these mechanisms utilises the Faraday's effect whereby the relative movement of a stationary magnet and coil winding will induce emf. Energy harvesters can be categorised into three groups: resonance harvesters, slider harvesters with a mobile coil or magnet, comprising a mobile core made of austenite steel and subjected to pressures (Kaleta 2013).

This study investigates the performance of linear or rotary magnetic harvesters and the authors focus on their potential applications as velocity sensors. It is a well established fact that emf induced in harvesters as a result of relative motion of a stationary magnet with respect to the coil is proportional to velocity, so a harvester can serve as a velocity sensor. In the context of research objectives set by the authors, these harvesters are to be employed in energy harvesting MR dampers exhibiting selfpowered and self-sensing capabilities. An overview of literature on the subject reveals a growing number of research reports in this area. For example, Jung et al. 2010 studying a sensing capability of the harvester incorporated in the MR damper-based vibration control system showed that a harvester could well serve as a velocity sensor for common control methods in such systems. Wang et al. 2010 proposed an integrated relative displacement self-sensing MR damper to realise the integrated relative displacement sensing and controllable damping. Chen and Liao 2010 reported the feasibility of engineering an MR damper with the power generation feature, integrating energy harvesting, dynamic sensing and MR damping technologies in a single device. Also, Chen and Liao 2012, performed theoretical and experimental studies of an MR damper prototype which had both self-powered and self-sensing capability. Li et al. 2013 presented an innovative concept of a mechanical motion rectifier converting bidirectional into unidirectional motion.

The present study recalls former works of the first author investigating energy harvesting MR dampers (Sapiński 2008, Sapiński 2014), exploring their applications in vibration reduction systems (Sapiński et al. 2016) and in positioning systems (Sapiński et al. 2018). The objective of the work is to demonstrate ability of the considered magnetic harvesters to act as velocity sensors. The study is organised as follows. Section 2 and 3 focus on the structural components of the linear and rotary harvester respectively. Section 4 explores the self-sensing capability of the devices basing on numerical and experimental data. The main conclusions are synthesised in Section 5 .

\section{LINEAR HARVESTER}

Sectional view and schematic diagram of the harvester are shown in Figs $1 \mathrm{a}, \mathrm{b}$. The harvester is symmetrical, incorporating a cylindrical coil with two-section winding and three arrays of ringshaped permanent magnets. Each array consists of three magnets moving inside an immobile coil. Ring-shaped magnets are magnetised axially. They are mounted on a shaft made of a nonferromagnetic material. In between the magnet systems are ringshaped ferromagnetic spacers. The magnet diameter is identical to that of the spacer. Coil winding sections are wound with copper foil, with one-sided insulation on the carcass. They feature the same height and the name of turns 273 . The middle point along the height of the two sections coincides with the point half-way 
between the magnet arrays. Coil sections are connected such that emfs induced in them should sum up. The coil is placed inside a housing made of ferromagnetic material. Dimensions of the key components of the harvester are compiled in Table 1. The height of an air slit between the carcass and the system of magnets is 1 $\mathrm{mm}$. Inductance of the coil windings is $0.141 \mathrm{H}$ and resistance $2.45 \Omega$. A more detailed specification is provides elsewhere (Sapiński 2014).

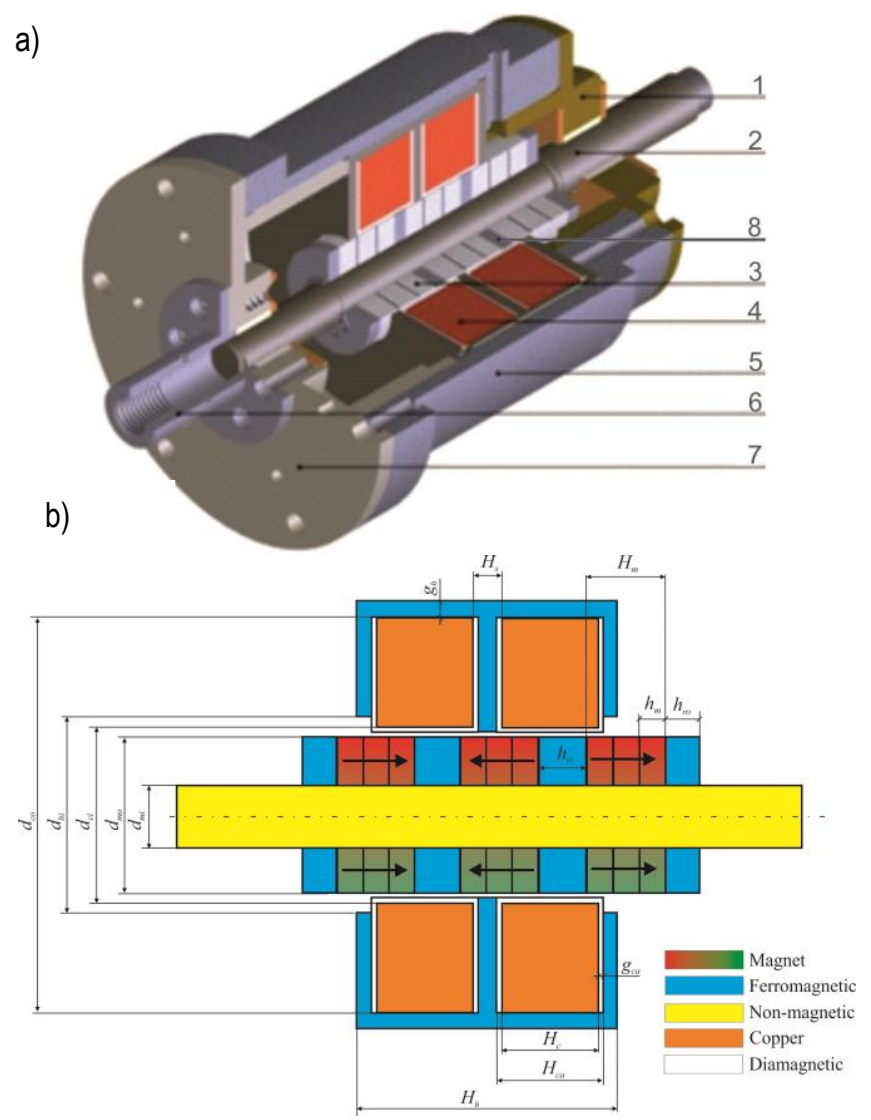

Fig. 1. Linear harvester: a) sectional view: 1 - upper cover, 2 - shaft, 3 - magnets, 4 - coil, 5 - housing, 6 - fixture, 7 - lower cover, 8 - spacer; b) schematic diagram

Tab. 1. Geometry of linear harvester components

\begin{tabular}{|l|l|l|}
\hline \multirow{4}{*}{ Magnet } & Height $h_{m}$ & $5 \mathrm{~mm}$ \\
\cline { 2 - 3 } & Inside diameter $d_{m i}$ & $20 \mathrm{~mm}$ \\
\cline { 2 - 3 } & Outside diameter $d_{m e}$ & $80 \mathrm{~mm}$ \\
\hline \multirow{5}{*}{ Coil } & Height $H_{c}$ & $54 \mathrm{~mm}$ \\
\cline { 2 - 3 } & Inside diameter $d_{c i}$ & $86 \mathrm{~mm}$ \\
\cline { 2 - 3 } & Outside diameter $d_{c e}$ & $127.6 \mathrm{~mm}$ \\
\cline { 2 - 3 } & Copper foil width $w_{f}$ & $50 \mathrm{~mm}$ \\
\cline { 2 - 3 } & Copper foil thickness $g_{f}$ & $0.05 \mathrm{~mm}$ \\
\cline { 2 - 3 } & Insulation width $w_{i}$ & $54 \mathrm{~mm}$ \\
\cline { 2 - 3 } & Insulation thickness $g_{i}$ & $0.03 \mathrm{~mm}$ \\
\hline \multirow{4}{*}{ Carcass } & Outside height $H_{c a}$ & $58 \mathrm{~mm}$ \\
\cline { 2 - 3 } & Wall thickness $g_{c a}$ & $2 \mathrm{~mm}$ \\
\hline Spacer & Height $H_{g}$ & $20 \mathrm{~mm}$ \\
\hline \multirow{2}{*}{ Coil housing } & Height $H_{h}$ & $86 \mathrm{~mm}$ \\
\cline { 2 - 3 } & Thickness $w_{h}$ & $3 \mathrm{~mm}$ \\
\hline
\end{tabular}

\section{ROTARY HARVESTER}

Sectional view (longitudinal and lateral cross-sections) and schematic diagram of the harvester are shown in Figs $2 a, b$. The harvester is symmetrical and incorporates a rotor and stator. The rotor is cylindrical in shape and is made of a non-ferrous material. Inside the rotor is a thin-walled cylinder made of ferromagnetic metal plate. On the cylinder there are 28 permanent magnets arranged along its circumference forming 14 pairs of poles. Major components of the harvester's electric circuits are placed inside the cylinder. The rotor is mounted on ball bearings and set on the shaft to which the stator is attached.

a)

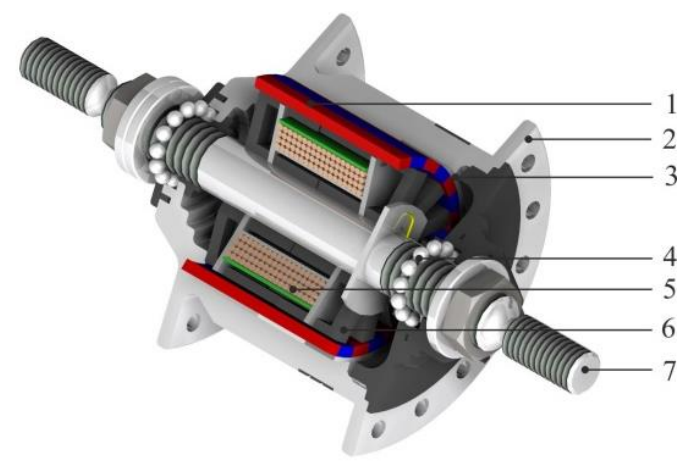

b)
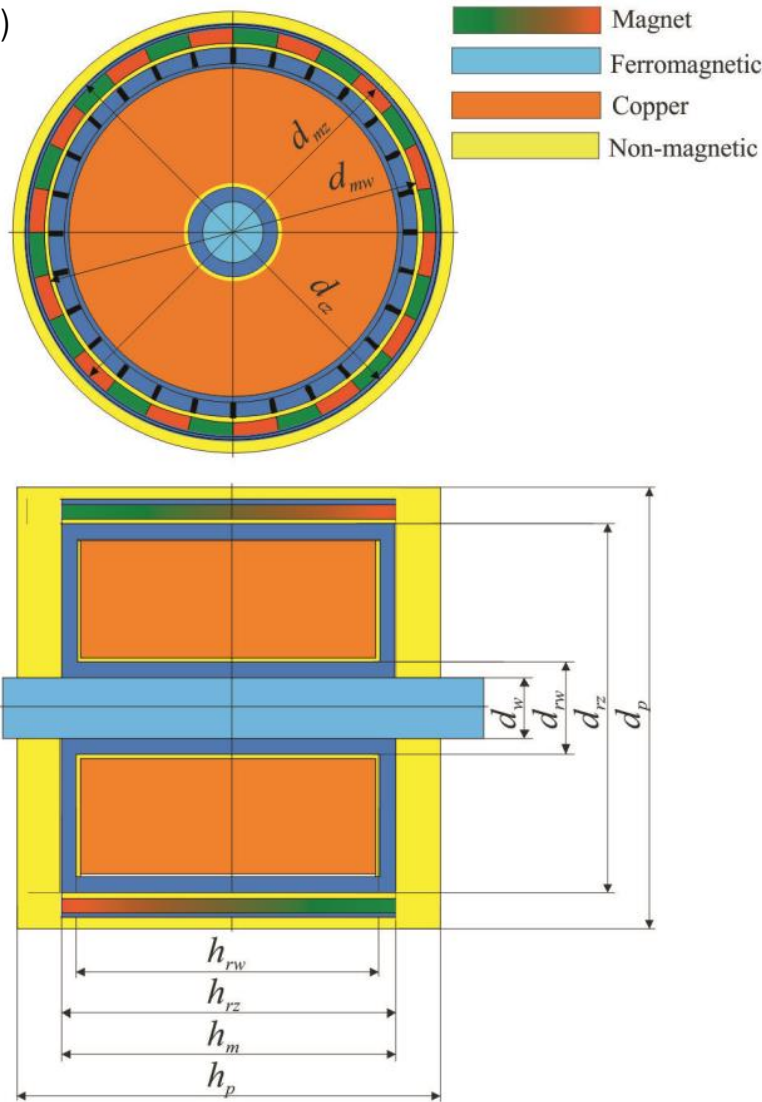

Fig. 2. Rotary harvester: a) sectional view: $1-$ cylinder, 2 - rotor , 3 - magnets, 4 - bearings, 5 - coil, 6 - stator, 7 - shaft; b) schematic diagram

The stator incorporates 14 pairs of rectangular frames (corresponding to the number of magnet poles), made of laid up ferromagnetic metal plates. Frames are arranged on the shaft radially and attached to the carcass made of an electrically insulating material. Each frame consists of two parts connected inside the 
windings and configured such that each part should correspond to one of the poles. Angular displacement between the frames approximates $\sim 13^{\circ}$. The winding made of 306 turns is placed inside the frames. It is wound upon the carcass (in the direction normal to the frames) with a wire $0.2 \mathrm{~mm}$ in diameter. The winding core comprises those frame sections inside the core which are in direct contact with the shaft. There is one cable outlet from the harvester whilst the other cable is connected to the shaft. Major components of a rotary harvester and their dimensions are listed in Table 2. The height of an air slit between the rotor and stator is $1 \mathrm{~mm}$, coil inductance is $0.031 \mathrm{H}$ and resistance $2.7 \Omega$. A more detailed description of the energy harvester is provided elsewhere (Matras et al. 2017).

Tab. 2. Geometry of rotary harvester components

\begin{tabular}{|c|l|r|l|}
\hline \multirow{4}{*}{ Sheet pack } & Internal diameter & $d_{r w}$ & $24.7 \mathrm{~mm}$ \\
\cline { 2 - 4 } & External diameter & $d_{r z}$ & $51.7 \mathrm{~mm}$ \\
\cline { 2 - 4 } & Internal height & $h_{r w}$ & $24 \mathrm{~mm}$ \\
\cline { 2 - 4 } & External height & $h_{r z}$ & $31 \mathrm{~mm}$ \\
\hline \multirow{4}{*}{ Magnet } & Internal diameter & $d_{m w}$ & $54 \mathrm{~mm}$ \\
\cline { 2 - 4 } & External diameter & $d_{m z}$ & $61 \mathrm{~mm}$ \\
\cline { 2 - 4 } & Height & $h_{m}$ & $31 \mathrm{~mm}$ \\
\hline \multirow{3}{*}{$\begin{array}{c}\text { Other } \\
\text { compnents }\end{array}$} & Shaft diameter & $d_{w}$ & $12 \mathrm{~mm}$ \\
\cline { 2 - 4 } & Harvester diameter & $d_{p}$ & $66 \mathrm{~mm}$ \\
\cline { 2 - 4 } & Harvester height & $h_{p}$ & $35 \mathrm{~mm}$ \\
\cline { 2 - 4 } & Cylnder external diameter & $d_{c z}$ & $63 \mathrm{~mm}$ \\
\hline
\end{tabular}

\section{RESULS OF NUMERICAL AND EXPERIMENTAL TESTS}

To best illustrate the potentials of energy harvesters, the results of numerical and experimental tests are compared under the idle run. The purpose of the tests was to establish the relationship between electromotive force and velocity across the harvester. In the case of a linear harvester, the amplitude of the applied sine and triangular excitation is assumed to be $5 \mathrm{~mm}$, excitation frequency falls in the range 1-7 Hz in $1 \mathrm{~Hz}$ intervals. In the case of a rotary harvester, its rotational speed is assumed to fall in the range $20-200 \mathrm{rpm}$ in $20 \mathrm{rpm}$ intevals.

The calculation procedure was conducted in the MATLAB environment (Sapiński 2014) and (Matras et al. 2017).

\subsection{Velocity Sensing in Linear Harvester}

Calculated (C) and measured (M) time histories of emf and velocity in the relative time $(t \times f)$ at frequency $1 \mathrm{~Hz}$ and $7 \mathrm{~Hz}$ are shown in Figs 3-6, revealing good correspondence between numerical and experimental data obtained under sinusoidal and triangle kinematic excitations. Time histories of velocity and emf within a single period were subjected to the harmonics analysis implicating that in order to obtain information about velocity, the 1st harmonic of the emf needs to be considered. Plots in Fig. 7 present the dependence of the velocity's 1-st harmonic on emf. This relationship is found to be linear in the analysed velocity range, evidencing that the harvester can well serve as a velocity sensor in this velocity range.

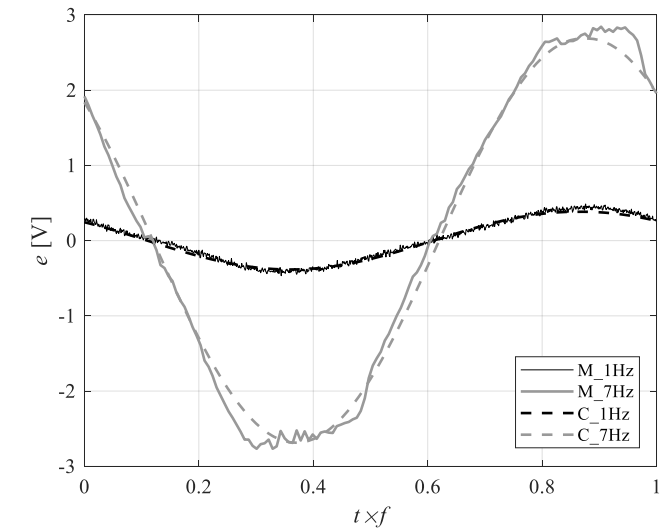

Fig. 3. Time histories of emf: sinusoidal input

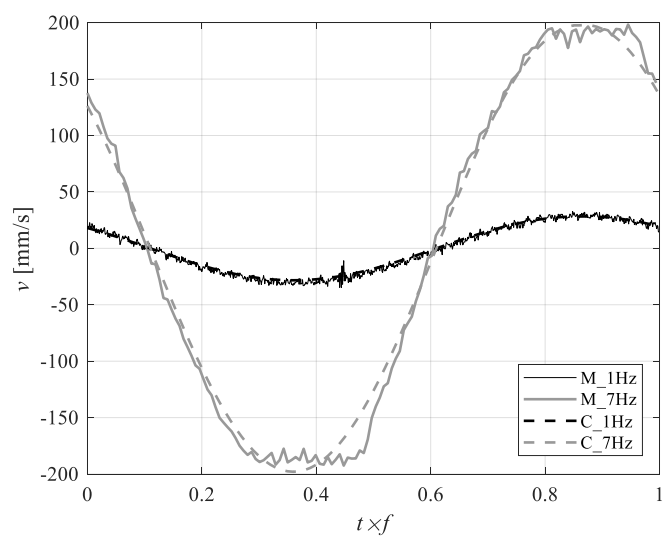

Fig. 4. Time histories of velocity: sinusoidal input

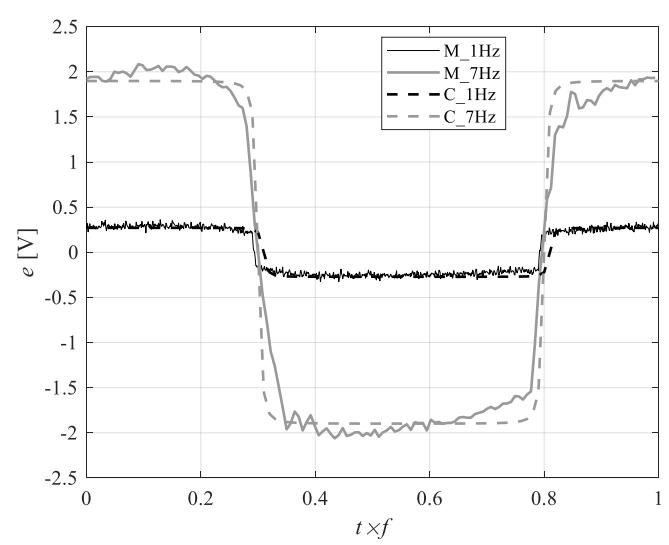

Fig. 5. Time histories of emf: triangle input

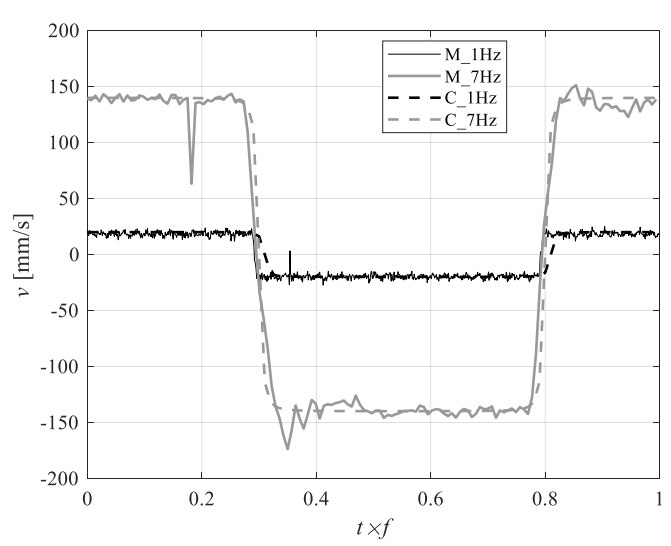

Fig. 6. Time histories of velocity: triangle input 


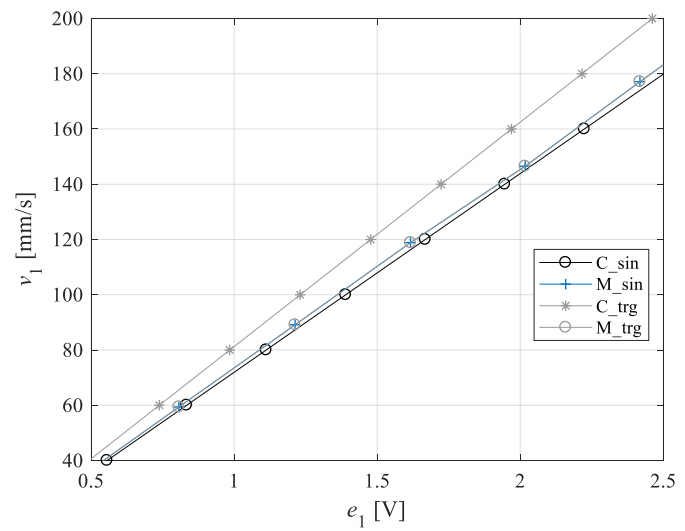

Fig. 7. Velocity vs emf

\subsection{Velocity sensing in rotary harvester}

Calculated $(\mathrm{C})$ and measured $(\mathrm{M})$ time histories of emf obtained in the relative time $(t \times f)$ at 20 and $200 \mathrm{rpm}$ are shown in Fig. 8. It is worthwhile to mention that the investigated velocity range is broader in comparison to the linear harvester tests. It is reasonable to expect that calculation and measurement data obtained at higher velocities might not show such good agreement. Plots in Fig. 9 present that the velocity dependence on the 1-st harmonic is linear.

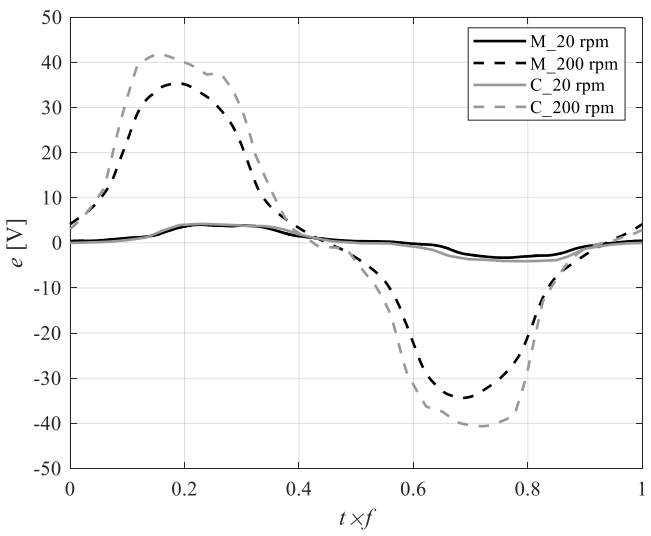

Fig. 8. Time histories of emf

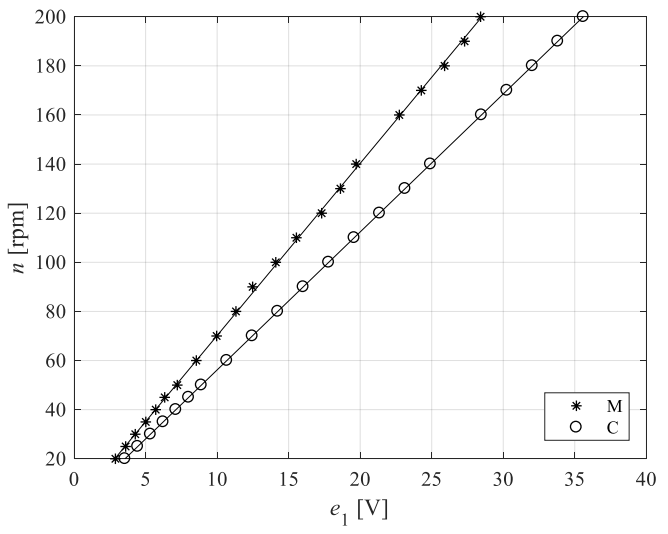

Fig. 9. Velocity vs emf

\section{SUMMARY}

The study investigates the performance of linear and rotary harvesters. Research efforts were aimed to establish the relationship between emf and velocity across the analysed devices via numerical procedures and laboratory testing of harvesters under the idle run. Numerical and experimental results are found to be in good agreement. Discussion of results leads us to the conclusion that power generation by energy harvesters can provide information about velocity, which can be utilised in MR damper-based vibration control systems with self-powered and self-sensing capabilities.

\section{REFERENCES}

1. Chen C., Liao W.H. (2010), A self-powered, self-sensing magnetorheological damper, Proceedings of IEEE Conference on Mechatronics and Automation, 1364-1369.

2. Chen C., Liao W.H. (2012), A self-sensing magnetorheological damper with power generation, Smart Materials and Structures, 21 025014.

3. Jung H.J., Jang D.D., Koo J.H., Cho S.W. (2010), Experimenta evaluation of a 'self-Sensing capability of an electromagnetic induction system designed for MR Dampers, Journal of Intelligent Material Systems and Structures, 21, 827-835.

4. Kaleta J. (2013), Magnetic materials SMART: Structure, manufacturing, testing, properties, applications., Oficyna Wydawnicza Politechniki Wrocławskiej.

5. Li Z, Zhuo L, Luhrs G, Lin L., Qin Y.( 2013), Electromagnetic energy harvesting shock absorbers: design, modeling and road tests, IEEE Transactions Vehicle Technology, 62, 1065-74.

6. Matras A., Sapiński B., Węgrzynowski M. (2017), Magnetic field and circuit analysis in an electromagnetic transducer supplying a rotary MR dumper, Przeglad Elektrotechniczny, 93, 145-149.

7. Sapiński B. (2008), An experimental electromagnetic induction device for a magnetorheological damper, Journal of Theoretical and Applied Mechanics, 46(4), 933-947.

8. Sapinski B. (2014), Energy harvesting MR linear damper: prototyping and testing, Smart Materials and Structures, 23, 035021.

9. Sapinski B., Rosół M., Węgrzynowski M. (2016), Investigation of an energy harvesting MR damper in a vibration control system, Smart Materials and Structures, 25, 125017.

10. Sapiński B., Węgrzynowski M., Nabielec J. (2018), Magnetrheological damper-based positioning system with power generation, Journal of Intelligent Material Systems and Structures, DOI: 10.1177/1045389x17730928

11. Wang D.H., Bai X.X., Liao W.H. (2010), An integrated relative displacement self-sensing magnetorheological damper: prototyping and testing, Smart Materials and Structures, 19, 105008.

This work is supported by AGH University of Science and Technology under research program No. 11.11.130.766. 